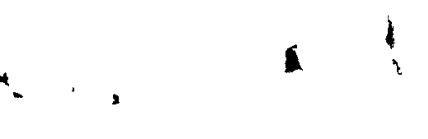

$\mathrm{AD}$

Award Number: MIPR 1DCB8F1067

TITLE: Remote Echocardiography: Proof of Concept for support of National Disasters, Combat and Humanitarian Mission

PRINCIPAL INVESTIGATOR: Sheri Yvonne Nottestad Boyd

CONTRACTING ORGANIZATION: Brooke Army Medical Center

Fort Sam Houston, Texas 78234-6200

REPORT DATE: November 2001

TYPE OF REPORT: Midterm

PREPARED FOR: U.S. Army Medical Research and Materiel Command Fort Detrick, Maryland 21702-5012

DISTRIBUTION STATEMENT: Approved for Public Release;

Distribution Unlimited

The views, opinions and/or findings contained in this report are those of the author(s) and should not be construed as an official Department of the Army position, policy or decision unless so designated by other documentation. 


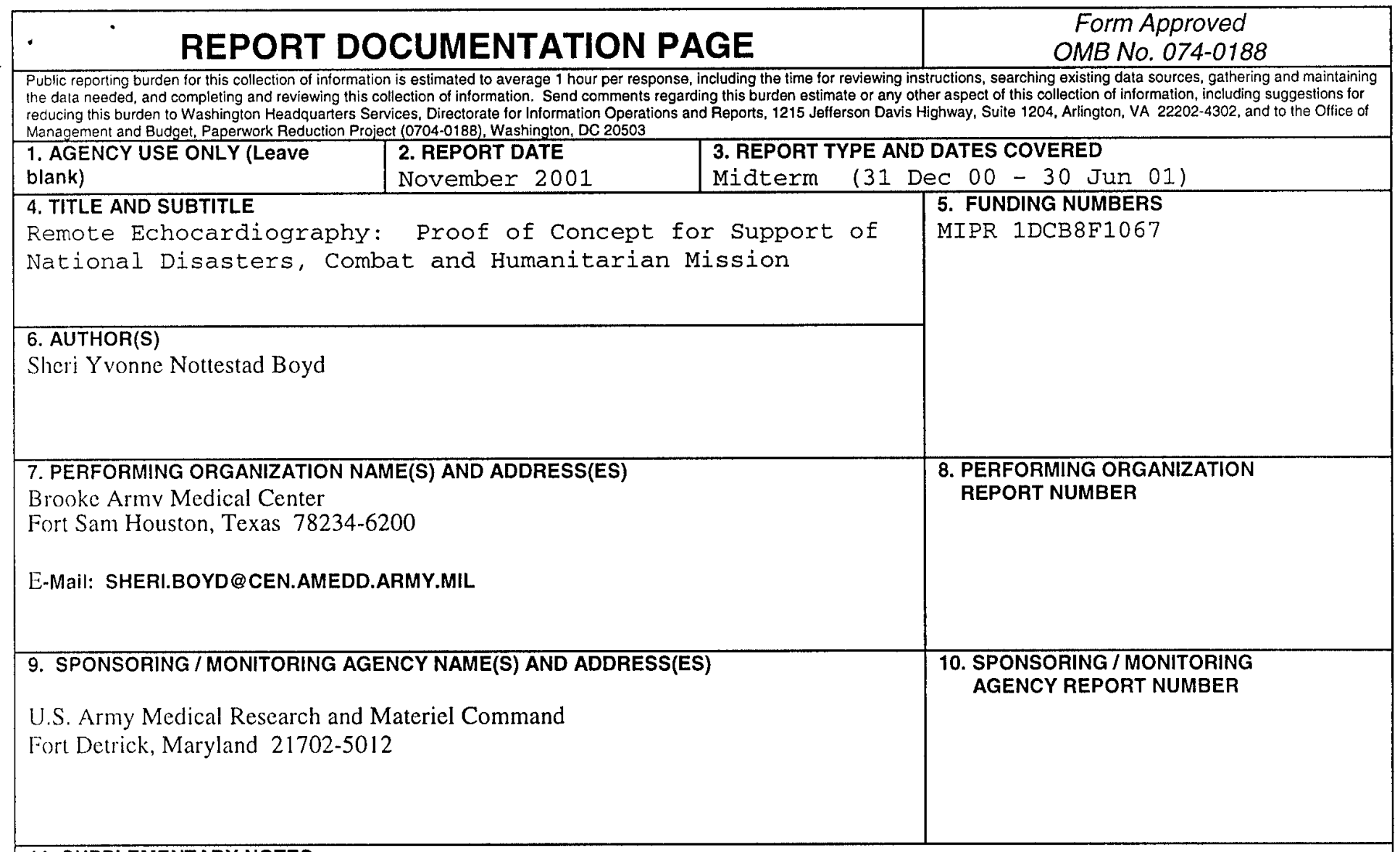

11. SUPPLEMENTARY NOTES

12a. DISTRIBUTION / AVAILABILITY STATEMENT

Approved for Public Release; Distribution Unlimited.

12b. DISTRIBUTION CODE

13. ABSTRACT (Maximum 200 Words)

\begin{tabular}{|c|c|c|c|}
\hline $\begin{array}{l}\text { 14. SUBJECT TERMS } \\
\text { Remote Echocardiograp }\end{array}$ & & & $\begin{array}{c}\text { 15. NUMBER OF PAGES } \\
6\end{array}$ \\
\hline $\begin{array}{l}\text { 17. SECURITY CLASSIFICATION } \\
\text { OF REPORT } \\
\text { Unclassified }\end{array}$ & $\begin{array}{l}\text { 18. SECURITY CLASSIFICATION } \\
\text { OF THIS PAGE } \\
\text { Unclass ified }\end{array}$ & $\begin{array}{l}\text { 19. SECURITY CLASSIFICATION } \\
\text { OF ABSTRACT } \\
\text { Unclassified }\end{array}$ & $\begin{array}{l}\text { 20. LIMITATION OF ABSTRACT } \\
\text { Unlimited }\end{array}$ \\
\hline NSN 7540-01-280-5500 & & & $\begin{array}{l}\text { ndard Form } 298 \text { (Rev. 2-89) } \\
\text { cribed by ANSI Std. Z39-18. } \\
102\end{array}$ \\
\hline
\end{tabular}


Table of Contents

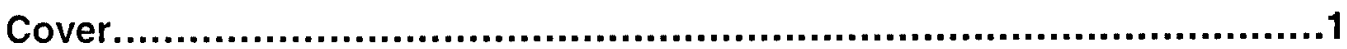

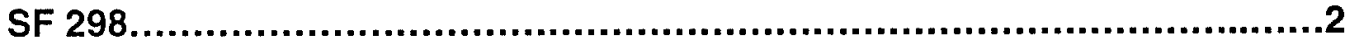

Accomplishments.............................................................4

Problems...................................................................4

Life-Cycle.........................................................................5

Deliverables........................................................................5

Expenditures......................................................................5

Financial Narrative.............................................................6 


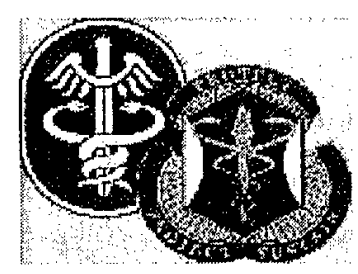

\section{MidTerm Overall Evaluation Report}

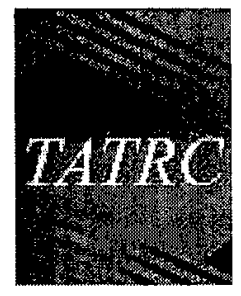

PROPOSAL: 2000000051

TITLE: Renote Echocardiography: Proof of Concept for Support of National Disasters, Combat and Humanitarian Mission

Mileposts:

\section{ACCOMPLISHMENTS}

31JAN01 P8 award MIPR on books at BAMC.

15FEB01 demonstration in BAMC Emergency Dept. of LifeLink (ambulance wireless) system.

05MAR01 test of serial transmission of SonoSite digital frames using ISR equipment

27MAR01 Satecho personnel visit to Southwest Research Institute (Sterling Kinkler). 1 9APR01 Test transmission of wireless video images, relayed via INMARSAT from FSHTX field. Also field test for ALI Newport small echocardiographic digitization unit (store/forward)

12JUN01 Test of higher-power wireless video transceiver (tactical vest), digital video recorder with INMARSAT for FAST exam protocol.

JUL01 Coordination of VSAT vendor, TATRC and BAMC IMD personnel for Camp Bullis testing.

14-16AUG Live patient field test, Camp Bullis. Transmission of echo images via VSAT (1.4Mbps and $76 \mathrm{Kbps})$, INMARSAT (56Kbps). Live video \& store $\&$ forward.

SEP 01 MASCAL exercise, San Antonio military personnel. Evaluation of echo (live and store/forward) using LifeLink ambulance telemedicine system

As the timeline above outlines, the project has been very active and included initial testing to develop a working wireless vest to allow portable handheld echo units to be moved and used in a MASCAL or CSH setting. Once developed this unit was tested locally for its ability to interface with portable satellite units. Finally an actual simulated MASCAL and CSH scenario was developed using facilities at Camp Bullis, TX. Patients with actual cardiac disease were transported to the site and imaged in the $\mathrm{CSH}$ with our portable echo units and wireless vest. Images were transmitted to BAMC via VSAT and INMARSAT and interpreted by cardiologist in real-time and later reivewed in a blinded fashion for diagnostic accuracy. Currently we are analyzing data and preparing manuscripts for publication which will outline our experience, and results. Initial data was presented at the ARMY ACP meeting and well recieved.

PI's Accomplishment Evaluation: : Project Accomplishments Match Proposal

\section{PROBLEMS}

Signficant difficult was encountered obtaining final approval from U. S. Army Medical Research \& Materiel Command, HSRRB. While funding was allocated in Jan 01- actual approval to enroll patients did not occur until Aug01. These delays wer multifactorial and included a 3 month backlog in protocols at USAMRMC and different IRB requirements at both the local BAMC vs HSRRB.

PI's Problem Area Evaluation: : 


\section{- LIFE-CYCLE}

The project has fulfilled its goals of demonstrating the feasibilty, diagnostic accuracy, and critical equipment and limitations of remote digital echocardiography in simulated MASCAL and CSH enviroments. Proposals to deploy this technology with active military units is the next step but would require funding- preproposals submitted for fiscal year 2002 were not accepted. No further testing or research under this proposal will be done at this time as project as designed is complete. The second half of the project will involve data analysis, and manuscript preparation for eventual publication in a trauma or military journal. Ideally, if funding exists, the project would be expanded to support a deployed medical unit.

PI's Life-Cycle Evaluation: : Project encountered no significant problems/issues

\section{DELIVERABLES}

Data will be published on the diagnostic accuracy of remote echocardiograms compared to studies obtained in a fixed facility in both a CSH and MASCAL setting. Published papers will outline the feasibility of remote digital echocardiography using currently available INMARSAT technology, current portable and hand-held echo imaging machines. Actual patients with known cardiac disease were imaged and evaluated in a functioning CSH (included a MASCAL scenario) at Camp Bullis. Actual patients with known cardiac disease were imaged and these were the images used for transmission of a MASCAL scenario from a moving ambulance using hand-held echo technology.

This data has implications for actual field unit testing of hand-held echocardiograms. Units equipped with satellite transmission would be able to send images to a receiving CONUS fixed facility with cardiologist for interpretation. The success of transmission, the ability to identify cardiac abnormalities would extend the diagnostic and therapeutic capabilities of remotely deployed units.

PI's Deliverables Evaluation: : Deliverable is on schedule per Proposal

\section{Expenditures}

Element of Resource (EOR)

Travel 2100

Shipping 2200

Rent \& Communications 2200

Contract for Services

2500

Supplies

2600

Equipment

3100
1ST Quarter

Oct 1 - Dec 31

$\$ 0.00$

$\$ 0.00$

$\$ 0.00$

$\$ 0.00$

$\$ 0.00$

$\$ 0.00$ 2nd Quarter

Jan 1 - Mar 31

$\$ 0.00$

$\$ 0.00$

$\$ 0.00$

$\$ 0.00$

$\$ 0.00$

$\$ 0.00$ 
actual cost POC/Comments 63,000.00 DICOM, cart, VCR, stress pkg 2,319.65 w/ battery, charger, cable (VISA) 10,870.95 w/ vest, camera,antenna, Li-ion battery, charger, cables 9,393.00 trade-in of CLI codec $8,849.971,300.00$ w/o monitor, 7 cassettes 7,500.00 projected by T. Morris: $\$ 7,5008,784.00$ audio 2-way, VTC compatible 34,712.00 TC305, TC308 closets $6,750.00$ Sterling Kinkler 2,800.00

TC-308 LifeLink connection for Cardiology 8,805.00 C. Dobard, Jim Pugliese, (713) 683-3320 328.00 Lisa Hayes 2,048.00 Faye Tawil. Incl. $32 \mathrm{DV}$ tapes 500.00 2,032.00 169,992.57 170,000.00 The project was completed within budget, the remaining task of data analysis and manuscript preparation will not require any additional funds. The equipment required for the project- namely the portable echo machine and a wireless transmitter vest were acquired and worked well throughout the project. Funding was allocated to Mr Tommy Morris to support the exercise in the CSH- this required personnel and satellite equipment to be shipped to Camp Bullis, TX. Mr Sterling Kinkler recieved funding to support use of the Transguide system to transmit echo images from a moving ambulance.

PI's Financial Evaluation: : Deliverable is on schedule per Proposal

\section{* END OF REPORT *}

